\title{
Puuvartiset maanpeitekasvit viherrakentamisessa
}

\author{
Sirkka Juhanoja \\ MTT puutarhatuotanto, Toivonlinnantie 518,21500 Piikkiö, sirkka.juhanoja@mtt.fi
}

\begin{abstract}
Johdanto
Viherrakentamisen ongelma-alueita ovat erilaiset liikenneväylien ympäristöt. Niiden kunto ja ulkonäkö ovat merkittäviä maiseman yleisvaikutelman muodostumisessa, mutta niiden pitäisi pysyä siisteinä vähällä hoidolla. Hankalat maastomuodot, kuivuus ja liikenteen aiheuttama kuormitus asettavat erityisvaatimuksia käytettäville kasveille, joiden pitää olla peittäviä ja reheviä muodostamatta kuitenkaan liian korkeita kasvustoja näkyvyyttä heikentämään. Tällaiset kohteet edellyttävät tavallisesti massaistutuksia eli suurta määrää saman lajin taimia. Tämän vuoksi istutusten onnistumisella on suuri paitsi esteettinen, myös taloudellinen merkitys. Käyttämällä kullekin lajille edullisinta taimikokoa voidaan työn sujuvuutta parantaa ja saada aikaan säästöjä. Matalat, maanpinnan tehokkaasti peittävät, usein kasvutavaltaan suikertavat pensaat ovat yksi kasviryhmä, jolla on mahdollisuuksia menestyä kyseisissä paikoissa.

Vuosina 1998-2003 MTT:ssa selvitettiin matalien puuvartisten pensaiden soveltuvuutta maanpeitekasveiksi kaupunkien viherrakentamiskohteissa yhdessä Viherympäristöliiton, Taimistoviljelijöiden ja Helsingin, Kuopion, Lahden, Mikkelin, Tampereen ja Turun kaupungin viheryksiköiden kanssa. Tavoitteena oli löytää liikennealueiden välikaistoilla ja erilaisissa luiskissa menestyviä, helppohoitoisia ja näyttäviä kasveja, jotka kestävät mekaanista rasitusta, pakokaasuja, aurauslumen painoa, hiekoitushiekkaa ja tallausta. Toisena tavoitteena oli saada tietoa näiden kasvien taloudellisimmasta taimikoosta ja istutustiheydestä. Parhaat kasvit saavat FinE ${ }^{\circledR}$-tavaramerkin käyttöoikeuden.
\end{abstract}

\section{Aineisto ja menetelmät}

Kokeissa oli mukana kasveja suvuista Chaenomeles, Cotoneaster, Diervilla, Euonymus, Potentilla, Prunus, Ribes, Rosa, Rubus, Salix, Spiraea, Stephanandra ja Viburnum.

Hanke koostui kolmesta osasta: vertailukoe, menestymiskoe ja käyttökokeet. Vertailukoe toteutettiin Piikkiössä $\left(60^{\circ} 23^{\prime} \mathrm{N}, 22^{\circ} 33^{\prime} \mathrm{E}\right)$, jossa 36 peittopensaskantaa istutettiin neliömetrin suuruisiin koeruutuihin pellolle. Näistä havainnoitiin kasvien perusominaisuudet, talvenkestävyys, korkeus, kukinta, yleisvaikutelma ja kasvuston peittävyys. Kokeessa käytettiin kahta taimikokoa ja kahta istutustiheyttä. Kookkaammat olivat kolmen litran astioissa kasvatettuja astiataimia, pienemmät puolen litran astioissa kasvatettuja kevyttaimia. Astiataimia istutettiin kolme kappaletta neliömetrille, kevyttaimia kolme tai viisi kappaletta neliömetrille. Valo- ja varjo-olosuhteiden mukainen tilanne luotiin peittämällä osa koeruuduista varjostuskangaskehikoilla.

Menestymiskokeeseen istutettiin samoja kasveja pellolle neliömetrin suuruisiin koeruutuihin MTT:n Pohjois-Pohjanmaan tutkimusasemalle Ruukkiin $\left(64^{\circ} 40^{\prime} \mathrm{N}, 25^{\circ} 05^{\prime} \mathrm{E}\right)$. Tästä kokeesta saatiin tietoa kasvien ilmastollisesta kestävyydestä.

Käyttökokeet perustettiin kaupunkien todellisiin viherrakentamiskohteisiin kaupunkien yleisen käytännön mukaisella tavalla. Kohteita perustettiin vuonna 1998 kuuteen kaupunkiin yhteensä 30, ja niissä oli noin 250 istutusryhmää. Kohteet olivat erilaisia katualueen viherkaistoja, puistoja ja luiskia erilaisilla paikoilla. Osassa kohteita käytettiin erilaisia istutustiheyksiä ja katekangasta. Vuonna 2002 perustettiin vielä yhteen kaupunkiin kolme uutta kohdetta, joissa käytettiin aikaisemmin istutettuja lajeja kevyttaimina. Näissä istutuksissa oli osassa hakekate, osassa suodatinkangas- ja sepelikate.

Kasvien arviointiin käytettiin silmämääräistä havainnointia, jossa oli apuna numeroasteikko, mittauksia ja peittävyyksien laskemista tarkoitusta varten kehitetyn havainnointikehikon avulla. Peittävyydet laskettiin prosentteina pinta-alasta yhden neliömetrin alalta. Peittävyys käsitti levittäytyneisyyden ja täyspeittävyyden. Levittäytyneisyydellä tarkoitettiin kasvin esiintymistä ruudussa, täyspeittävyydellä prosentteina sitä aluetta, minkä kasvi peittää siten, että kasvualustaa ei näy suoraan ylhäältä päin tarkasteltuna. Käyttökokeiden havainnoinnissa kiinnitettiin erityistä huomiota kasvien helppohoitoisuuteen ja niiden selviytymiseen erilaisten ympäristörasitteiden keskellä. Tällaisia asioita ovat tallaus, aurausvahingot, hiekoitushiekan ja lumen kasautuminen, tiesuola, pakokaasut, rikkakasvit ja mekaaniset kulutusvauriot.

Peltokokeiden tulosten laskentaan käytettiin SAS- ja Excel-ohjelmistoja ja kaupunkien tiedot koottiin tietokannaksi Access-ohjelmalla. 


\section{Tulokset ja niiden tarkastelu}

Osa kasveista osoittautui jo ensimmäisinä vuosina maanpeittotarkoitukseen soveltumattomiksi. Tässä yhteydessä esitellään vain kasvit, jotka parhaiten soveltuvat siihen tarkoitukseen, mikä tutkimuksessa oli tavoitteena.

\section{Matalia peittopensaita}

Mattopaju Salix $\times$ aurora (S. x finnmarchica) on matala uutuuspaju. Sen lehdet ovat pienet, tummanvihreät ja kiiltävät ja muistuttavat tuhkapensaan lehtiä. Versot ovat voimakkaan punaruskeat. Emikukinnot aukeavat aikaisin keväällä, yhtäaikaa lehtien puhkeamisen kanssa. Pensas on koheneva, noin 40-50 cm:n korkuinen. Aurinkoisella paikalla pensaat kasvavat tuuheimmiksi. Mattopaju on talvehtinut erinomaisesti kaikilla koepaikoilla, eikä kasvustoissa ole havaittu merkittäviä tuholaisia tai merkkejä kasvitaudeista. Tällä pajulla voitaisiin korvata monessa tapauksessa matalat tuhkapensaat.

Toinen matala, hieman koheneva uutuuspaju, jota ei ole aikaisemmin käytetty viherrakentamisessa, on paljakkapaju S.glauca var. callicarpaea. Pensaan korkeus on noin 30-40 cm. Lehdet ovat harmaanukkaiset ja versot punertavat. Keväällä heti lehtien puhkeamisen jälkeen ilmestyvät kukinnot ovat pehmeän harmaanukkaisia. Syysväritys on kirkkaankeltainen, mutta sillä ei ole maisemallista merkitystä, koska lehdet varisevat nopeasti värittymisen jälkeen. Pensaat ovat talvehtineet erinomaisesti myös Ruukissa, talvivaurioita ei ole havaittu missään koeistutuksissa. Laji on myös melko terve, mutta joillakin paikoilla on esiintynyt vähän ruostetta. Tämä paju viihtyy aurinkoisella paikalla läpäisevässä maassa.

Molemmat uutuuspajut ovat nopeasti levittäytyviä lajeja. Jo ensimmäisenä havaintovuonna sekä Piikkiön valo- ja varjoruuduissa että Ruukin kokeessa molempien lajien levittäytyneisyys oli lähes $100 \%$. Kevyttaimi-istutuksissa mattopaju oli parempi: tiheään istutetuissa ruuduissa kasvustoa oli noin $62 \%: s s a$ alasta, paljakkapajulla noin $46 \%$ :ssa alasta. Molemmilla lajeilla harvempi kevyttaimi-istutus oli levittäytynyt vain noin $30 \%$ :iin alasta. Täysin peittävää (täyspeittävyys $100 \%$ ) kasvustoa pajut eivät muodosta eivätkä juurru helposti oksista kasvualustaan, ja tämän vuoksi ne onkin aiheellista istuttaa katekankaaseen. Molemmat lajit voidaan istuttaa tiheään kevyttaimista. Uutuuspajut tulevat markkinoille omine lajikenimineen.

Seppelvarpua Stephanandra incisa 'Crispa' on pidetty melko talvenarkana kasvina, mutta koepensaat ovat talvehtineet hyvin mm. Kuopiossa. Sen sijaan Pohjois-Pohjanmaalla kasvu on ollut kituvaa. Seppelvarvut lähtivät huomattavasti paremmin kasvamaan isoista astiataimista kuin kevyttaimista. Vuosi istutuksen jälkeen astiataimet olivat levittäytyneet valoruutuihin $97 \%$ :sesti, varjoruutuihin 100 $\%$ :sesti ja seuraavana vuonna sekä valo- että varjoruutuihin noin $100 \%$ :sesti. Kevyttaimilla istutustiheys vaikutti selvästi levittäytymiseen ensimmäisenä vuonna: tiheäistutuksen arvo oli $48 \%$, harvaistutuksen 18 $\%$. Harvaan istutetuista ruuduista oli kuollut taimia, mikä vaikutti tuloksiin. Toisena vuonna tiheäistutus oli levittäytynyt jo $79 \%$ :iin alasta. Seppelvarpu peitti parhaiten varjossa. Täyspeittävyys oli varjoruuduissa kaksinkertainen valoruutuihin verrattuna. Markkinoilla on ilmeisesti eri seppelvarpukantoja, jotka poikkeavat toisistaan jossakin määrin kestävyyden suhteen. Selvää näyttöä parhaasta kannasta ei kuitenkaan saatu. Laji sopii sekä aurinkoon että puolivarjoon, mutta koepaikoilla etenkin puolivarjoisten kasvupaikkojen kasvustot ovat kehittyneet näyttäviksi. Syysväri puolestaan on kaunein aurinkoisilla paikoilla. Seppelvarpu on syytä istuttaa astiataimista, ja se hyötyy selvästi katteen käytöstä.

\section{Suikertavia lajeja}

Lamohietakirsikka Prunus pumila var. depressa sopii parhaiten aurinkoiseen, jopa paahteiseen kasvupaikkaan. Kasvin talvenkestävyys on erinomainen, ja pensas saa suojaa ohuestakin lumipeitteestä. Lamohietakirsikat ovat nopeasti levittäytyviä pensaita. Isot valotaimet levittäytyivät kasvupaikalleen täysin jo ensimmäisenä havaintovuonna ja kevyttaimetkin istutustiheydestä riippumatta parissa vuodessa. Lamohietakirsikoiden lehdet ovat kapeita ja asennoltaan yläviistoon suuntautuvia. Kasvusto näyttää silmämääräisesti peittävältä, mutta mittaamalla täyspeittävyyden arvot jäävät isoillakin taimilla vain muutamaan prosenttiin. Maanmyötäisen kasvutapansa takia lamohietakirsikka kärsii helposti rikkakasvien kilpailusta ja varjostuksesta. Puhtaammilla kasvupaikoilla niin puisto-, luiska- kuin katukohteissakin laji on muodostanut lähes peittäviä kasvustoja. Kasvustosta tulee nopeasti peittävän näköinen, mutta se vaatii siistinä pysyäkseen katekankaan tai hakkeen. Lamohietakirsikka voidaan istuttaa myös pieninä kennotaimina, jolloin tiheään istutettu kasvusto saavuttaa nopeasti astiataimista perustetun istutuksen 
kanssa samanlaisen peittävyyden.

Pikkuherukka Ribes glandulosum on suikertavasti kasvava ja noin 40-50 cm:n korkuinen. Sen lehdet puhkeavat huhtikuussa ja kukinta ajoittuu alkukesään. Tuleentuminen tapahtuu aikaisin, kuivina kesinä jo elokuussa. Aikaisen tuleentumisen takia kasvustot eivät ole edustavia syksyllä. Laji soveltuu erityisesti paikoille, joissa sen varhaiskevään vihreys pääsee oikeuksiinsa eikä aikaisesta tuleentumisesta ole haittaa. Pikkuherukka on hyvin talvenkestävä, ja se menestyi erinomaisesti Pohjois-Pohjanmaallakin. Pitkien versojensa ja nopean kasvun ansiosta pikkuherukka levittäytyy tehokkaasti. Vuoden kuluttua istutuksesta astiataimiruudut olivat levittäytyneisyydeltään noin $100 \%$ sekä valossa että varjossa. Kevyttaimien vastaavat arvot olivat noin 30-40\%, eikä istutustiheydellä tai kannalla juuri ollut vaikutusta. Pikkuherukkakasvustojen täyspeittävyys ei yleensä ole $100 \%$, vaikka kasvustot näyttävätkin maisemassa peittäviltä. Tämän vuoksi katteiden käyttö on tällekin lajille eduksi. Versot juurtuvat toisinaan kasvualustaan. Istutuksiin voidaan käyttää kennotaimia. Pikkuherukkakantojen välillä on eroja, jotka liittyvät lähinnä kasvuston korkeuteen, lehtimuotoon ja tuleentumisajankohtaan, eivät niinkään kestävyyteen.

Sinivatukka Rubus caesius on rehevä- ja nopeakasvuinen viherpensas. Se on voimakas kilpailija, joka tukahduttaa helposti muun kasvillisuuden alleen. Nopeakasvuiset ja pitkäversoiset sinivatukat levittäytyvät kasvupaikalleen nopeasti. Isot taimet valtasivat koeruutunsa kokonaan ja levittäytyivät naapuriruutuihinkin jo ensimmäisenä vuonna. Kevyttaimikasvustot saavuttivat saman tilanteen toisena vuonna. Sinivatukkakasvustojen täyspeittävyys kehittyi kahdessa vuodessa kohtalaisen hyväksi. Valossa kasvaneilla isoilla taimilla peittävyys oli noin $40 \%$. Varjossa kasvustot olivat tätäkin peittävämpiä. Kevyttaimi-istutuksissa istutustiheys vaikutti selvästi täyspeittävyyden kehittymiseen. Sinivatukka sopii parhaiten paikoille, joissa sen leviämistä ei tarvitse rajoittaa, sekä laajoille istutusalueille massakasviksi, koska sen piikkiset versot ovat jopa 4 m pitkiä. Kasvuston korkeus on noin $80 \mathrm{~cm}$, jopa $1 \mathrm{~m}$. Liikennealueilla pitkät versot saattavat tielle levitessään vaatia leikkausta. Sinivatukan talvenkestävyys on ollut vaihteleva, mutta Helsingin kaupungin Keskas-kanta on kestävä ja elinvoimainen. Kennotaimien käyttö istutuksissa on mahdollista. Kate ei ole tiheässä istutuksessa välttämätön.

\section{Verhopensaita}

Vuohenkuusamalajit ovat hyviä peittopensaita. Ne tulevat noin metrin korkuisiksi ja ovat kasvutavaltaan pensasmaisia ja hyvin tiheitä. Eri lajien käyttötapa ja -kohde ovat samat, ja lajit muistuttavat paljon toisiaan, mutta niiden välillä on eroja, joita voidaan suunnittelussa käyttää hyväksi. Rusovuohenkuusama Diervilla sessilifolia on kasvutavaltaan hyvin tiheä, tasainen, pensasmainen ja noin metrin korkuinen. Keväällä lehdet ovat väriltään punaruskeat. Kukat ovat vihertävänkeltaiset ja muuttuvat vanhetessaan lämpimänkeltaisiksi. Keltavuohenkuusama D.lonicera on suunnilleen samankokoinen kuin rusovuohenkuusama, mutta hieman harvakasvuisempi. Lehdet ovat keväällä heleänvihreitä. Kukat ovat nuorina lämpimänkeltaisia ja muuttuvat vanhetessaan punaisiksi. Lamovuohenkuusama $D$. x splendens on ruso- ja keltavuohenkuusaman risteymä, ja lehti- ja kukkaominaisuuksiltaan se on kantalajiensa välimuoto. Kasvutavaltaan se on kuitenkin rennompi. Kookkaat lehdet ovat nuorina sävyltään keltaisia ja kukat ovat aluksi vihertävänkeltaisia, mutta punertuvat vanhetessaan.

Vuohenkuusamien arvo viherrakentamisessa perustuu niiden rehevään ja peittävään lehdistöön. $\mathrm{Ne}$ ovat todellisia peittopensaita. Vuohenkuusamat levittäytyvät kasvupaikalleen melko nopeasti juurivesojen avulla. Piikkiössä kaikilla kannoilla valo- ja varjoruuduissa kasvusto levittäytyi koko ruutuun jo ensimmäisenä vuonna. Kevyttaimi-istutuksissa parhaiten levittäytyivät rusovuohenkuusama ja lamovuohenkuusama. Istutustiheydellä ei ollut vaikutusta levittäytymiseen. Rehevän kasvutavan ja juurivesojen ansiosta vuohenkuusamakasvustot kehittyvät nopeasti peittäviksi. Ensimmäisenä vuonna valoruutujen täyspeittävyys vaihteli eri kannoilla $9-18 \%$ välillä. Varjoruuduissa peittävyys oli noin $30 \%$. Kevyttaimikasvustoissa täyspeittävyys kehittyi hitaammin kuin isoilla taimilla.

Lisäarvoa vuohenkuusamille tuo vuodenaikojen mukaan vaihtuva lehdistön väritys. Kukinta, vaikka onkin runsas ja pitkään jatkuva, vaikuttaa pensaan ulkonäköön melko vähän. Kaikkien vuohenkuusamien versot ovat hauraita. Pensaat tuottavat kuitenkin runsaasti juurivesoja, jotka korvaavat nopeasti katkeilleet versot. Hauraiden versojen vuoksi vuohenkuusamat eivät kestä raskasta lumikuormaa. Ränsistyneet kasvustot voidaan siistiä alasleikkaamalla. Liikennepaikkojen näkemäalueille vuohenkuusamat ovat liian korkeita, mutta ne soveltuvat erinomaisesti massapensaiksi monenlaisiin ympäristöihin sekä aurinkoon että varjoon ja ovat parhaimmillaan puolivarjossa. Kaikki lajit ovat terveitä. Keltavuohenkuusama talvehti melko hyvin Pohjois-Pohjanmaallakin, jossa ruso- ja lamovuohenkuusama saivat vioituksia ankarina talvina, etenkin syksyn 2002 ja talven 2003 aikana, mutta pensaat ovat toipuneet 
hyvin. Vuohenkuusamat on varminta istuttaa astiataimina, eivätkä ne tarvitse välttämättä katekangasta. Vuohenkuusamista on olemassa erilaisia kantoja, joiden välillä on menestymiseroja. Massaistutuksiin on syytä käyttää vain tutkittuja Suomessa menestyviä kantoja, jotka tulevat markkinoille omine lajikenimineen.

Kokeessa mukana olleet pensashanhikit Potentilla ovat kasvutavaltaan melko matalia, noin 60-80 $\mathrm{cm}$ korkeita, tuuheita ja tiheästi haarovia. Keltakukkaiset kannat ovat Elizabeth-lajiketta, vaaleakukkainen Dart's Cream -lajiketta, ja heleänvihreälehtiset ja erittäin kirkkaankeltakukkaiset pensaat Goldteppichlajiketta. Käyttöominaisuuksiltaan eri lajikkeet ovat toisiaan vastaavia. Kaikki kokeen kannat levittäytyivät jo ensimmäisenä havaintovuonna lähes koko koeruudun alueelle. Kevyttaimilla istutustiheys näkyi selvästi levittäytyneisyydessä: harvaistutuksissa arvot olivat noin 45-55 \% ja tiheäistutuksissa noin 70-80 \%. Vuoden kuluttua istutustiheyden vaikutus ei enää näkynyt vaan kaikki kevyttaimi-istutukset olivat levittäytyneet käytännöllisesti katsoen koko ruutuun. Pensashanhikkien täyspeittävyys kasvoi nopeasti ensimmäisen havaintovuoden aikana ja kevyttaimi-istutukset saavuttivat astiataimien täyspeittävyyden.

Pensashanhikit talvehtivat hyvin ja olivat kohtalaisen terveitä Pohjois-Pohjanmaallakin. Lievällä kirva-, punkki- ja härmäsaastunnalla ei ollut vaikutusta pensaiden koristearvoon tai menestymiseen. Pensashanhikit levittäytyvät sivusuuntaan melko hitaasti, minkä vuoksi ne on syytä istuttaa tiheästi. Pensashanhikkikasvusto voidaan perustaa myös kennotaimista. Katekankaasta on hyötyä, mutta tiheään istutettu kasvusto menestyy ilmankin.

\section{Johtopäätökset}

Tulosten perusteella maanpeitekasveiksi soveltuvia pensaita on useita. Tuotantoon voidaan ottaa 2-4 meillä tähän asti viljelemätöntä lajia tai lajiketta ja lisätä 4-6 jo tuotannossa olevan pensaan määriä. Tuloksilla on merkitystä taimitarhatuotannon kannalta. Rakennetun ympäristön vihreytykseen hyvät lajit tuovat vaihtelua ja viljelyvarmuutta. Viljelyvarmuus ja helppohoitoiset kasvustot merkitsevät säästöjä sekä materiaali- että työkustannuksissa kaupunkien ja kuntien viheryksiköille. Tulosten perusteella voidaan myös valita eri lajeille ja eri kohteisiin edullisin taimikoko. Erilaisten katekankaiden ja niiden pinnalle levitettävien kateaineiden käytöstä saatiin myös lupaavia kokemuksia, mutta tämä kokonaisuus edellyttäisi vielä lisäselvityksiä. Eri taimikokojen käyttö voi johtaa uudenlaisen viljelykäytännön kehittämiseen viheralalla, eli lyhyellä viljelyajalla tuotettavien kenno- tai kevyttaimien tilaustuotantoon. 